\title{
Formação inicial de professores de inglês e as Tecnologias Digitais de Informação e Comunicação (TDICs).
}

\begin{abstract}
We aim to address in this article a work experience with the initial training of English teachers and Digital Information and Communication Technology. Therefore, we will address the importance of using technology in language teaching, aspects of initial training and present a practical experience of initial training carried out with students from a federal university who attended the course of English letters. After presenting some theoretical assumptions, we will present an action research conducted in a Federal Public University in the discipline of Discursive Practices of Everyday Life. Finally, we will present the results of data analysis and our final thoughts on the Digital Information and Communication Technology applied to language teaching and teacher training.
\end{abstract}

Keywords: Digital Information and Communication Technology. Initial Teacher Trainig.

Resumo. Temos como objetivo neste artigo abordar uma experiência de trabalho com a formação inicial de professores de inglês e as Tecnologias Digitais da Informação e Comunicação (TDICs). Para tanto iremos abordar a importância de utilizar a tecnologia no ensino de línguas, aspectos da formação inicial e apresentar uma experiência prática de formação realizada com alunos de uma universidade federal que frequentavam o curso de Letras Inglês. Após discorrermos sobre alguns pressupostos teóricos, iremos apresentar uma pesquisa-ação realizada em uma Universidade Pública Federal na disciplina de Práticas Discursivas do Cotidiano. Por fim, apresentaremos os resultados da análise de dados e nossas considerações finais sobre as TDICs aplicadas ao ensino de línguas e à formação docente.

Palavras-chave: Tecnologias digitais da informação e comunicação. Formação inicial de professores.

\section{Introdução}

A sociedade do século XXI enfrenta novos desafios e está sujeita a reestruturações, consequentes de inclusões de nanotecnologias em nosso cotidiano. Isso faz com que tenhamos que lidar com um número muito maior e mais complexo de informações e sejamos capazes de realizar diferentes tarefas relacionadas à tecnologia, como a utilização de relativamente simples terminais bancários, com também celulares smartphones e seus inúmeros aplicativos e, acima de tudo, a Internet.

A Internet transpôs barreiras geográficas e abriu fronteiras educacionais, tornando possível o encontro e a troca de experiências entre diferentes culturas e a possibilidade de parcerias antes inimagináveis (LEWIS, 2003). Por meio dela, muitos 
conhecimentos podem ser compartilhados e experiências de aprendizado colaborativas se tornam mais acessíveis.

Por conseguinte, fez-se necessário que o sistema educacional se transformasse para acompanhar as mudanças ocorridas nos estilos de vida contemporâneos. É essencial que a educação aborde as características tecnológicas presentes nesse modelo de sociedade digital, a qual requer da população outros conhecimentos que englobem relações interpessoais mais complexas, tanto nos eventos pessoais quanto profissionais. De fato, cada vez mais os cidadãos estão em contato com um número muito maior de informações e precisam estar preparados para saber selecioná-las, analisá-las e utilizálas.

A estrutura educacional, portanto, deve começar a preparar os aprendizes desde a mais tenra idade para lidar com as exigências cotidianas, formando profissionais mais autônomos, colaborativos, críticos e dispostos a lidar com as diversas tecnologias, que continuarão a surgir no decorrer dos anos.

Desta forma, temos como objetivo neste trabalho abordar uma experiência de trabalho com a formação inicial de professores de inglês e as tecnologias digitais. Para tanto iremos abordar a importância de utilizar a tecnologia no ensino de línguas, aspectos da formação inicial e apresentar uma experiência prática de formação inicial realizada com alunos de uma universidade federal que frequentavam o curso de Letras inglês.

\section{A tecnologia e o ensino de línguas}

Ao longo dos anos, os educadores têm presenciado significativas mudanças na maneira como a língua é ensinada. Teorias e práticas fazem com que o ensino e aprendizado evoluam e mudem seu foco de geração em geração. Gramática, escrita, produção oral, comunicação, aspectos culturais e muitos outros já foram enfatizados em momentos distintos da trajetória da língua estrangeira (LE), mas agora nossa atenção é direcionada a mais uma ferramenta inovadora e de ampla utilidade: o uso de tecnologias digitais.

Com a expansão das tecnologias computacionais em nossas atividades diárias, a sociedade em que vivemos tem sido descrita como a "sociedade da informação" por causa de sua infraestrutura essencialmente baseada nas TDICS, em computadores e em sistemas comunicacionais eletrônicos (GODDARD, 2002; HONEY, 2001; POLONOLI, 2001 apud KTORIDOU; ETEOKLEOUS-GRIGORIOU, 2011).

Viver nesta sociedade da informação é inquestionavelmente desafiador e Poore (2011) nos aponta que uma das maiores mudanças é precisamente o que está ocorrendo nos âmbitos comunicacionais, econômicos e políticos. Mas também encontramos mudanças mais culturais relacionadas com nossas tradições, experiências, arte, ciência e linguagem (POORE, 2011).

$\mathrm{O}$ acesso à Internet, as pesquisas em sites de busca, as trocas de e-mails, as interações em redes sociais, fazem parte da rotina das pessoas do século XXI. Com a redução dos preços dos computadores pessoais e de celulares smartphones, o avanço da tecnologia e da nanotecnologia, aparelhos cada vez mais eficientes e portáteis, equipados com sistema wireless, que capacitam as pessoas a se comunicar a qualquer hora e em qualquer lugar, são criados para nos auxiliar no trabalho e na vida pessoal. 
De acordo com Alves e Vieira (2015, p.239) "os atuais meios de comunicação internet, revistas, televisão - têm atualmente grande poder pedagógico, visto que aliam uma gama de recursos que oportunizam aos alunos agilidade e interatividade".

Assim, o ensino de línguas precisa estar em constante modernização para fazer parte desse mundo globalizado, visto que, de acordo com O'Rourke e Schwienhorst (2003), novas tecnologias mudam a maneira como as pessoas aprendem uma segunda língua, pois elas podem trabalhar com recursos diferentes no aprendizado.

\section{Formação inicial}

Considerando os novos paradigmas mundiais, a formação do professor de língua estrangeira foi repensada no sentido de capacitar um profissional que desempenhe várias habilidades e competências, preparado para construir uma prática pedagógica consciente e reflexiva com intuito de aperfeiçoar os processos de ensino e aprendizagem.

É na formação pré-serviço que começa a se construir a competência do futuro professor, e de acordo com Chaguri e Tonelli (2010) esta formação não tem preparado os professores para os contextos diversos em que atuará como profissional.

Por isso é importante que ainda durante a graduação os alunos sejam estimulados a desenvolver um processo reflexivo que esteja vinculado a questões de linguagem, papel do professor e construção social, pois só assim, o professor em préserviço terá a possibilidade de refletir sobre seu próprio processo de aprendizagem, que ele mesmo poderá desenvolver, estando voltado para uma compreensão crítica de seu trabalho como educador e profissional de Língua Estrangeira (CHAGURI; TONELLI, 2010, p. 2).

Entendemos que há uma grande necessidade da prática reflexiva se fazer presente na formação do professor, já que no Curso de Letras a função do profissional é também "fundamentar os licenciandos (futuros professores), fazendo-os conhecer e refletir criticamente sobre os elementos presentes numa situação de ensino aprendizagem" (CAMARGO, 1983, p.43).

Deste modo, a inclusão das Tecnologias Digitais de Informação e Comunicação (TDICs) nas atividades do Curso de Letras e outros cursos de formação de professores, e a consequente reflexão sobre o uso e a repercussão das mesmas no ensino e aprendizagem dos alunos-professores pode significar a formação de profissionais mais conscientes em sua prática pedagógica.

De acordo com Lima e Louveiro (2015, p.397)

A prática pedagógica contemporânea requer uma integração entre os saberes acadêmicos, os curriculares e a integração com as TDIC, pois as formações não podem se pautar em currículos onde não ocorra esta integração entre conhecimentos e tecnologias.

A mesma atenção também deve ser dada aos professores que já estão atuando. Muitos deles não tiveram a chance de entrar em contato com as novas metodologias durante seu período de formação e necessitam constante capacitação com o intuito de manter a sala de aula sempre atualizada. 
V Congresso Brasileiro de Informática na Educação (CBIE 2016)

Anais dos Workshops do V Congresso Brasileiro de Informática na Educação (CBIE 2016)

\section{Contexto da Pesquisa}

O trabalho em questão ocorreu em uma Universidade Pública Federal, no curso de Letras, durante o primeiro semestre de 2016, na disciplina de Práticas Discursivas do Cotidiano.

Motivados pela necessidade de instigar o pensamento crítico e trabalhar com o letramento digital entre os alunos de Letras, ainda em sua formação inicial, e com intuito de formar profissionais qualificados para atuar na sala de aula, programamos o semestre incluindo atividades online durante a extensão do mesmo. Optamos por utilizar como apoio a plataforma Moodle ${ }^{1}$, como também outras plataformas educativas propiciando várias atividades distintas.

Tivemos como participantes de pesquisa 18 aprendizes, sendo 10 do período matutino e 8 do período noturno. A disciplina foi organizada em 18 encontros, e no decorrer do semestre várias atividades foram propostas como fórum, quizes, gravação de voz e vídeo, atividades usando recursos do Moodle como exercícios de preenchimento de lacunas, exercícios de escrita, atividades utilizando o aplicativo Socrative ${ }^{2}$, incentivo de uso do celular para checagem de vocabulário e busca durante as aulas e uma atividade específica utilizando a plataforma colaborativa Padlet $^{3}$, que iremos focar neste trabalho.

A atividade em questão foi aplicada no dia 6 de Abril de 2016 e o trabalho se constitui em duas fases, a primeira presencial em sala de aula com leitura de textos, compreensão de vídeos e discussões em grupos e a segunda online, com o trabalho na plataforma Padlet.

O trabalho presencial se organizou da seguinte forma:

1) Primeiramente, os alunos foram separados em três grupos distintos. Ao primeiro grupo foi dado um extrato de um artigo de pesquisa sobre o inglês no mundo, ao segundo um artigo ${ }^{4}$ de uma publicação online sobre tecnologia no ensino e aprendizagem e ao terceiro grupo foram disponibilizados dois vídeos ${ }^{5}$ sobre a aprendizagem e as habilidades do século XXI. Em seus grupos os alunos trabalharam com o material e depois discutiram os conceitos com a sala toda.

2) Em seguida, foi apresentado aos alunos um extrato para discussão de um vídeo ${ }^{6}$ retirado do Ted Talk intitulado "Construa uma escola na nuvem" de Sugata Mitra.

3) A partir do vídeo discutimos conceitos de autonomia e suas aplicações no ensino e aprendizagem de línguas.

\footnotetext{
${ }^{1}$ https://pt.wikipedia.org/wiki/Moodle

2 http://www.socrative.com/

${ }^{3}$ https://padlet.com/

${ }^{4} \mathrm{http} / / / \mathrm{www}$.theguardian.com/teacher-network/teacher-blog/2014/may/12/technology-language-teachinglearning-pedagogy

${ }^{5} \mathrm{https}: / /$ www.youtube.com/watch?v=nA1Aqp0sPQo e

https://www.youtube.com/watch?v=f0RyaAsVNGU

${ }^{6} \mathrm{https}: / / \mathrm{www}$. youtube.com/watch?v=y3jYVe1RGaU
} 
4) Após essa etapa, foi disponibilizado aos alunos um texto de um $\operatorname{blog}^{7}$, escrito por Jeremy Harmer, que critica a proposta apresentada anteriormente no Ted Talk. Neste momento foi provocada a discussão sobre posicionamentos opostos dentro de metodologias de ensino e aprendizagem de línguas.

5) Como atividade para ser feita em casa, foi proposto aos aprendizes que eles escolhessem uma habilidade do século XXI discutida em sala de aula, pesquisassem uma ferramenta digital que pudesse ser usada no ensino e aprendizagem da língua inglesa e descrevessem uma atividade usando estes dois preceitos e postassem a mesma no Padlet para ser compartilhada e discutida com todos da sala.

Passemos, portanto, para os resultados e a discussão do trabalho.

\section{Resultados e Discussão}

O objetivo das atividades propostas na aula descrita acima era de despertar nos aprendizes o interesse pela discussão de uso de tecnologias digitais no ensino e aprendizagem de línguas. Todos os textos e vídeos apresentados carregavam essa temática e os alunos se mostraram bastante participativos e se engarajam nas discussões propostas.

Apesar do engajamento e colaboração nas atividades presenciais propostas, somente quatro alunos completaram a atividade online. Iremos, assim, descrever e analisar três destas atividades.

A aluna $\mathrm{Karina}^{8}$, de acordo com a sua postagem no Padlet, descreveu que sua atividade teve como intuito,

To improve students critical thinking, teamwork, autonomy, group collaboration, research skills, global awareness, multicultural literacy I would suggest them to work with webquest. Different types of research would be asked in this activity. In an English class, I would suggest students to work in groups with English speaking countries in the world. The webquest bellow exemplifies this activity. ${ }^{9}$

Deste modo, Karina escolheu trabalhar com as habilidades do século XXI de pensamento crítico, trabalho em time, autonomia, colaboração, habilidades de pesquisa, consciência global e letramento multicultural, combinando todas em uma única atividade. Ela sugeriu trabalhar com a ferramenta de webquest onde fora proposto que os alunos pesquisassem em grupos sobre países falantes da língua inglesa, o que geraria

\footnotetext{
${ }^{7}$ https://jeremyharmer.wordpress.com/2014/04/07/angel-or-devil-the-strange-case-of-sugata-mitra/

${ }^{8}$ Os nomes dos alunos mencionados são fictícios.

9 Tradução nossa: Para melhorar o pensamento crítico dos alunos, o trabalho em equipe, a autonomia, a colaboração em trabalho em grupo, as habilidades de pesquisa, a consciência global, o letramento multicultural. Eu sugeriria aos alunos trabalhar com o webquest. Diferentes tipos de pesquisa seriam demandados desta atividade. Em uma aula de Inglês, eu sugeriria que os alunos trabalham em grupos e pesquisassem os países falantes de língua inglesa do mundo. $O$ webquest abaixo exemplifica esta atividade. (http://zunal.com/webquest.php?w=128056)
} 
V Congresso Brasileiro de Informática na Educação (CBIE 2016)

Anais dos Workshops do V Congresso Brasileiro de Informática na Educação (CBIE 2016)

uma discussão depois que cada grupo postasse o seu trabalho. Como mediadora da discussão ela abordaria e reforçaria o uso das habilidades do século XXI propostas em seu objetivo.

A atividade de Karina foi bem elaborada e refletiu sua experiência como professora já atuante em uma escola de idiomas da cidade. Entretanto, a própria aprendiz relatou em sala de aula que caso fosse utilizar a ideia proposta, talvez a fizesse sem o apoio da ferramenta descrita (webquest), já que a mesma discussão poderia ser gerada com instruções impressas e com a utilização de ferramentas de buscas na internet.

A outra atividade que iremos descrever, foi proposta por Fabiana. A aprendiz optou por trabalhar com a habilidade de pensamento crítico sugerindo que os alunos usassem seus smartphones como descrito no Padlet,

In order to foster the critical learning hability I would ask students to search with their cell phones on the website http://www.debate.org/ the most controversial debate topics that are being discussed which they would like to discuss too. Based on students' choice I would send them during the week between the classes two texts with different opinions on the topic. At home students would have to read the texts, and read what people from around the world are saying on the debate forum, and also write their ideas, opinions on the topic debating it with others. On the next class students would talk about their experience on debating with people from different countries and what they like the most, who they talk to, and what they talked about. ${ }^{10}$

A proposta de Fabiana se mostra bem interessante pois inicia seu trabalho com o uso de smartphones. Na sociedade atual é bem comum que as pessoas possuam um aparelho celular com conexão à internet e algumas escolas oferecem o uso de wifi gratuito, assim os aprendizes não precisariam ter um bom pacote de dados para fazer a atividade.

A escolha do site de debates pode propiciar aos alunos o contato com outros falantes de inglês, nativos e não nativos, e a discussão de assuntos pertinentes a cada um deles, já que a opção do tópico do debate partiria dos estudantes. A professora entraria como mediadora propondo leituras e depois mediando o relato dos alunos sobre a experiência, o que também oportunizaria o

\footnotetext{
10 Tradução nossa: A fim de promover a habilidade de aprendizagem crítica pediria aos alunos que fizessem buscas com seus telefones celulares no site http://www.debate.org/ os temas de debate mais controversos que estão sendo discutidos que gostariam de discutir também. Com base na escolha dos alunos, entre uma aula e outra durante a semana, eu enviaria aos alunos dois textos com opiniões diferentes sobre o tema. Em casa, os alunos teriam que ler os textos e ler o que as pessoas de todo o mundo estão dizendo no o fórum de debates e também escrever as suas ideias e opiniões, debatendo o tema com outros. Na aula seguinte os alunos falariam sobre sua experiência sobre o debate com pessoas de diferentes países e o que eles gostaram mais, com quem falaram, e sobre o que falaram.
} 
desenvolvimento da autonomia e da tomada de responsabilidade por cada aprendiz.

Acima de tudo, como destaca Fabiana, a atividade poderia gerar o desenvolvimento do pensamento crítico do aprendiz, já que ele estudaria o assunto e entraria em contato com opiniões diversas provindas de falantes de todo o mundo, com realidades e culturas distintas.

Passemos para o terceiro trabalho apresentado pela aluna Mariana. A proposta de Mariana é trabalhar com o gênero diário digital. A princípio Mariana fornece um link para os alunos entenderem melhor o gênero e para que posteriormente construam seu próprio diário, como podemos ver em sua explicação no Padlet,

Writing a Diary. You will create a fictional diary. You will post it online, in a blog website. You should develop a character and a bunch of little stories about her/his life. You can use pics and/or videos to make it more interesting/funny. The project will last for two weeks. ${ }^{11}$

Como continuidade do projeto a Mariana propõem que os alunos se engajem em uma discussão guiada pelas seguintes perguntas:

Read the project of your classmates. Which one do you think it was the most interesting? Why? Do you believe the story could fit in the real life? Why? What was the differences and similarities beetwen the projects? ${ }^{12}$

Entendemos que a proposta de Mariana pode contemplar o trabalho das habilidades de criatividade, pensamento crítico, autonomia, busca de informação e construção de conhecimento. A atividade também pode ir de encontro a prática usual de estudantes de seguirem ou produzirem fanfics $^{13}$, dar liberdade para os alunos escolherem o tópico a ser trabalhado e oportunizar a divulgação de seu

\footnotetext{
${ }^{11}$ Tradução nossa: Escrevendo um diário. Você vai criar um diário ficcional. Você vai publicá-lo online, em um site de blog. Você deve desenvolver um personagem e um monte de pequenas histórias sobre sua vida. Você pode usar as fotos e/ou vídeos para torná-lo mais interessante/divertido. O projeto terá a duração de duas semanas.

${ }^{12}$ Tradução nossa: Leia o projeto dos seus colegas de sala. Qual deles você considera o mais interessante? Por quê? Você acredita que a estória poderia ocorrer na vida real? Por quê? Quais as diferenças e similaridades entre os projetos?

${ }^{13}$ Fanfiction, fanfic ou apenas fic é uma narrativa ficcional, escrita e divulgada por fãs em blogs, sites e em outras plataformas pertencentes ao ciberespaço, que parte da apropriação de personagens e enredos provenientes de produtos midiáticos como filmes, séries, quadrinhos, videogames, etc, sem que haja a intenção de ferir os direitos autorais e a obtenção de lucros. Portanto, tem como finalidade a construção de um universo paralelo ao original e também a ampliação do contato dos fãs com as obras que apreciam para limites mais extensos.(WIKIPEDIA, 2016)
} 
trabalho, que não teria como propósito somente a produção de texto para correção do professor, mas a divulgação de suas estórias entre os colegas de sala para apreciação e discussão.

O trabalho do quarto aluno que postou sua atividade no Padlet não foi registrado na plataforma. Esse mesmo problema foi relatado pelos outros três alunos que tiveram que postar a atividade duas vezes para que ela permanecesse na página do Padlet.

Partamos agora para as considerações finais.

\section{Considerações Finais}

Hoje em dia a disponibilidade de recursos tecnológicos que podem ser integrados e utilizados no ensino e aprendizagem de línguas é imensurável. Entretanto, devemos considerar que nem todos os professores e alunos têm acesso a essa tecnologia.

Nem todas as escolas oferecem acesso wifi aos alunos ou laboratórios com computadores que podem ser usados pelos mesmos. As instituições que oferecem nem sempre podem fornecer um acesso de qualidade por questões técnicas das próprias empresas que fornecem os serviços e quando tudo isso se encontra disponível, os próprios professores e/ou alunos podem não possuir a cultura ou letramento necessário para trabalhar com a tecnologia no ensino e aprendizagem de línguas.

Retomando a atividade proposta na formação de professores de línguas, dos 18 alunos matriculados na disciplina, somente quatro demonstraram interesse e completaram a atividade. $\mathrm{O}$ objetivo geral da atividade era fazer com que eles utilizassem as tecnologias digitais de informação e comunicação ao praticarem o que foi discutido em sala de aula, pesquisando, criando e compartilhando uma atividade que poderia contribuir com a própria formação, mas também com a formação do colega professor pré-serviço, o que não aconteceu na sua totalidade.

Raros são os momentos que essas práticas relacionadas com ensino e tecnologia são oportunizadas na formação de professores e poucos são os aprendizes que engajam-se nas atividades propostas. Ainda assim, o resultado dos trabalhos postados no Padlet e a discussão gerada em sala de aulas sobre estes trabalhos foi bem aceita e valorizada pelos alunos.

Percebemos que nem sempre os alunos se motivam a percorrer os caminhos do ensino de línguas e tecnologias talvez por falta de letramento digital ou por crenças derivadas de seu próprio aprendizado onde a realidade de trabalho com tecnologias não era recorrente.

Como exemplo, tivemos a dificuldade dos alunos que se propuseram a fazer a atividade de postá-la na plataforma, talvez por desconhecimento do aluno ou por um real problema na plataforma. Também observamos que apesar da 
V Congresso Brasileiro de Informática na Educação (CBIE 2016)

Anais dos Workshops do V Congresso Brasileiro de Informática na Educação (CBIE 2016)

plataforma oferecer vários recursos, somente três deles foram utilizados pelos aprendizes participantes da atividade, que foram a postagem de texto; a postagem de links e; a postagem de imagem. Assim mesmo os alunos incentivando o uso da tecnologia e da criatividade em suas atividades eles mesmos não optarem por utilizar tais recursos, como podemos ver na imagem do Padlet abaixo:

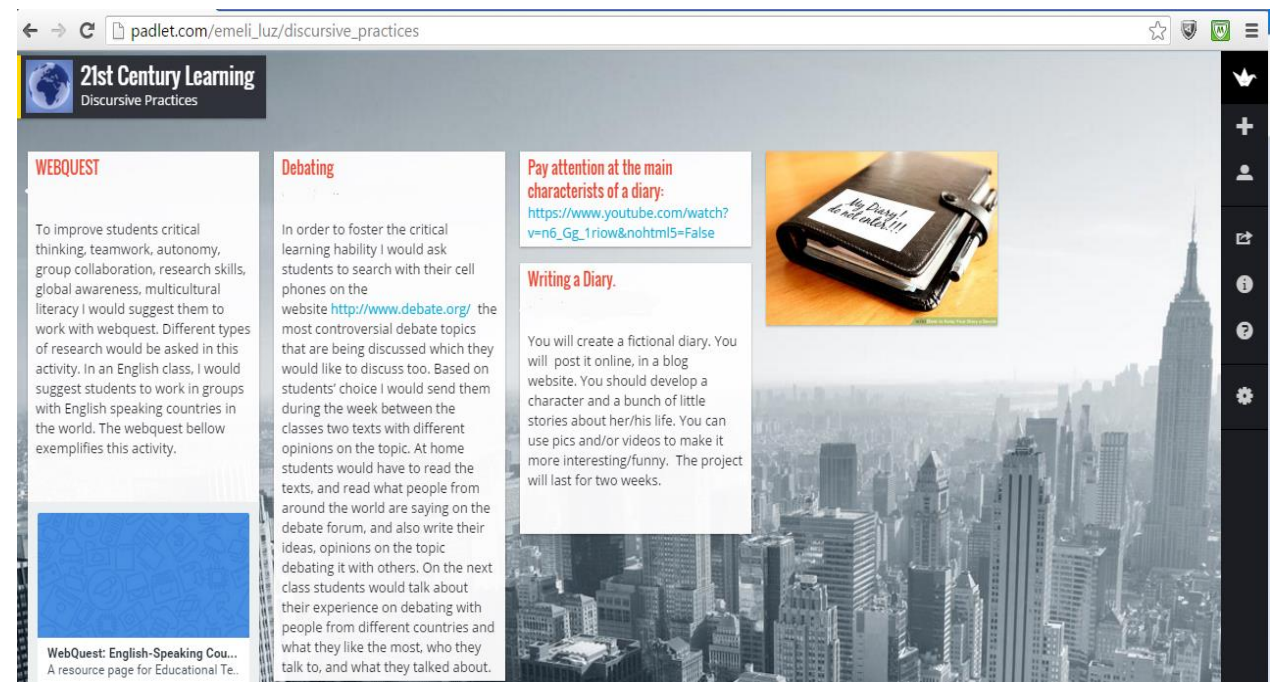

Figura 1. Print de tela do Padlet.

Portanto, defendemos que a formação de professores deve ser constantemente enriquecida com os adventos da tecnologia digital para que os professores assimilem e incluam tais conceitos e pressupostos em suas práticas.

Argumentamos também que hajam mudanças no currículo atual do curso de letras para que disciplinas relacionadas diretamente com letramento digital e ensino e aprendizagem e tecnologias digitais (contemplando também aspectos do ensino à distância) sejam incluídas de forma permanente no curso para possibilitar mudanças concretas na formação de professores, que possivelmente terão que lidar com essa realidade na prática de sua profissão nos séculos a seguir.

\section{Referências}

ALVES, E. D. G; VIEIRA, M. F. Celular e sala de aula: dos limites às possibilidades. In: CONGRESSO BRASILEIRO DE INFORMÁTICA NA EDUCAÇÃO, 4, 2015, Dourados, MS. Anais do XXI Workshop de Informática na Escola, 2015, p. 236 245). Disponível em: < http://www.br-ie.org/pub/index.php/wie/article/view/5029>. Acesso em: 15 de maio, 2015.

CAMARGO, D. A. F. A Didática nos cursos de formação de professores - um enfoque piegetiano, ANDES. São Paulo (9), n. 43-6, 1985. 
V Congresso Brasileiro de Informática na Educação (CBIE 2016)

Anais dos Workshops do V Congresso Brasileiro de Informática na Educação (CBIE 2016)

CHAGURI, J. P; TONELLI, J. R. A. Alguns aspectos teóricos e políticos sobre a forma- ção de professores de língua estrangeira. In: Colóquio internacional de estudos linguísticos e literários - CIELLI, 1º 2010, Maringá, Anais... Maringá, 2010.

FANFIC. In: Wikipedia: a enciclopédia livre. Disponível em:

<https://pt.wikipedia.org/wiki/Fanfic\#Refer.C3.AAncias>. Acesso em: 26 abril 2016.

GODDARD, M. "What do we do with these computers? Reflections on technology in the classroom". Journal of Research on Technology in Education. V. 35, n. 1, p. 1926, 2002.

HONEY, M. Testimony and statement for the record of Margaret Honey. Educational Development Center (2001). Disponível em:

<www.edc.org/spotlight/Tech/mhtestimony.htm>. Acesso em 30 jan. 2010.

KTORIDOU, D; ETEOKLEOUS-GRIGORIOU, N. Devoloping digital imigrant's computer literacy: the case of unemployed women. Emerald. Emeral Group Publishing Limited. V. 28, n. 3, p. 154-163, 2011.

LEWIS, T. The case for Tandem Learning. In: LEWIS, T.; WALKER, L. (Eds.) Autonomous Language Learning In-Tandem. Sheffield, UK: Academy Electronic Publications, 2003, p 13-26.

LIMA, L; LOUVEIRO, R. C. A integração entre docência e tecnologias digitais da informação e comunicação na formação de licenciandos. In: In: CONGRESSO BRASILEIRO DE INFORMÁTICA NA EDUCAÇÃO, 4, 2015, Dourados, MS. Anais do XXI Workshop de Informática na Escola, 2015, p. 395 - 404. Disponível em: $<$ http://www.br-ie.org/pub/index.php/wie/article/view/5062>. Acesso em: 15 de maio, 2015.

O'ROURKE, B.; SCHWIENHORST, K. Talking text: reflections on the reflections in computer-mediated communication. In: LITTLE, D.; RIDLEY, J.; USHIODA, E. (Eds) Learner autonomy in the Foreign Language Classroom: teacher, learner, curriculum and assessment. Dublin: Authentik, 2003, p.47-60.

POLONOLI, E. K. Integrating technology into classroom: three questions concerned principals must ask. Principal Leadership. V. 2, n.. 4, p. 34-8, 2001.

POORE, M. Digital Literacy: Human Flourishing and Collective Intelligence in a Knowledge Society. Literacy Learning: the Middle Years. V. 19, n. 2, p. 20-26, 2011. 